\title{
Characteristics of CALIOP attenuated backscatter noise: implication for cloud/aerosol detection
}

\author{
D. L. Wu ${ }^{1}$, J. H. Chae ${ }^{1,2}$, A. Lambert ${ }^{1}$, and F. F. Zhang ${ }^{3}$ \\ ${ }^{1}$ Jet Propulsion Laboratory, California Institute of Technology, Pasadena, California, USA \\ ${ }^{2}$ Joint Institute for Regional Earth System Science and Engineering, University of California, Los Angeles, California, USA \\ ${ }^{3}$ Harvard University, Cambridge, Massachusetts, USA
}

Received: 8 May 2010 - Published in Atmos. Chem. Phys. Discuss.: 15 July 2010

Revised: 28 February 2011 - Accepted: 17 March 2011 - Published: 22 March 2011

\begin{abstract}
A research algorithm is developed for noise evaluation and feature detection of the CALIOP (Cloud-Aerosol Lidar with Orthogonal Polarization) Level 1 (L1) backscatter data with an emphasis on cloud/aerosol features in the upper troposphere and lower stratosphere (UT/LS). CALIOP measurement noise of the version v2.01 and $\mathrm{v} 2.02 \mathrm{~L} 1$ backscatter data aggregated to $(5 \mathrm{~km})$ horizontal resolution is analyzed with two approaches in this study. One is to compare the observed and modeled molecular scatter profiles by scaling the modeled profile (with a fitted scaling factor $\alpha$ ) to the observed clear-sky backscatter profiles. This scaling $\alpha$ value is sensitive to errors in the calibrated backscatter and the atmospheric model used. Most of the nighttime 532-nm $\alpha$ values are close to unity, as expected, but an abrupt drop occurred in October 2008 in the daytime 532-nm $\alpha$, which is likely indicative of a problem in the v2.02 daytime calibrated data. The 1064-nm night $\alpha$ is generally close to 2 while its day $\alpha$ is $\sim 3$. The other approach to evaluate the lidar measurement noise is to use the calibrated lidar backscatter data at altitudes above $19 \mathrm{~km}$. With this method, the $532-\mathrm{nm}$ and 1064-nm measurement noises are analyzed and characterized individually for each profile in terms of the mean $(\mu)$ and standard deviation $(\sigma)$, showing larger $\sigma$ values in general over landmasses or bright surfaces during day and in radiation-hard regions during night. A significant increasing trend is evident in the nighttime 1064-nm $\sigma$, which is likely responsible for the increasing difference between the feature occurrence frequencies (532-nm vs. 1064-nm) derived from this study. For feature detection with the research algorithm, we apply a $\sigma$-based method to the aggre-
\end{abstract}

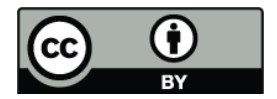

Correspondence to: D. L. Wu (dong.l.wu@jpl.nasa.gov) gated L1 data. The derived morphology of feature occurrence frequency is in general agreement with that obtained from the Level 2 (L2) $05 \mathrm{~km} \_$CLAY $+05 \mathrm{~km} \_$ALAY products at $5 \mathrm{~km}$ horizontal resolution. Finally, a normalized probability density function (PDF) method is employed to evaluate the day-night backscatter data in which noise levels are largely different. CALIOP observations reveal a higher probability of daytime cloud/aerosol occurrence than nighttime in the tropical UT/LS region for 532-nm total backscatters $>0.01 \mathrm{~km}^{-1} \mathrm{sr}^{-1}$.

\section{Introduction}

Cirrus and aerosol properties in the upper troposphere and lower stratosphere (UT/LS) region play an important role in climate-feedback processes (e.g., Jensen et al., 1996; Dessler et al., 2008). However, many aspects of cirrus remain unclear, including formation and lifecycle of these clouds in the tropopause layer (e.g., Jensen and Ackerman, 2006; Fueglistaler et al., 2009) and UT microphysics (Comstock et al., 2007). Potential impacts of changing UT aerosols are likely to further complicate interactions between cloud and water vapor in this region (Lohmann and Roeckner, 1995; Sherwood, 2002; Mishchenko et al., 2007). Thus, global observations of cloud/aerosol properties from the CALIOP (Cloud-Aerosol Lidar with Orthogonal Polarization) on CALIPSO (Cloud-Aerosol Lidar and Infrared Pathfinder Satellite Observation) are highly valuable for constraining this problem.

Rich information on cloud/aerosol properties and distributions has been obtained from CALIOP observations (Winker et al., 2003, 2007, 2009). Flying in the A-train orbit, the nadir dual-wavelength (532 and $1064 \mathrm{~nm})$ and

Published by Copernicus Publications on behalf of the European Geosciences Union. 
dual-polarization (perpendicular and parallel at $532 \mathrm{~nm}$ ) lidar has footprints collocated with CloudSat $94 \mathrm{GHz}$ Cloud Profiling Radar (CPR) (Stephens et al., 2002) and a suite of passive imagers/sounders. Since May 2008, Aura satellite moved up slightly in the A-Train such that the CALIOP and CloudSat measurements are aligned within the same curtain plane $( \pm 10 \mathrm{~km}$ in cross-track distance) where Aura MLS (Microwave Limb Sounder) makes limb measurements, which extended collocated cloud measurements to microwaves at submillimeter wavelengths (e.g., $640 \mathrm{GHz}$ and $2.5 \mathrm{THz}$ ). Together with the infrared (IR) and visible imagers/sounders, the collection of nearly-coincident-andcollocated A-train observations opens an unprecedented opportunity for cloud/aerosol research.

Like with other remote sensing techniques, cloud/aerosol detection with CALIOP depends on measurement noise, measurement volume, and threshold used. For unbiased cloud/aerosol detection, one would like to have a sensor with stable noise so that a constant threshold could be applied globally for feature detection. It is nearly the case for CloudSat reflectivity noise (Tanelli et al., 2008), but not for the CALIOP noise. The latter can vary largely from profile to profile, which makes the cloud/aerosol detection more challenging. A method with variable thresholds for feature detection must be used with care, because it could affect the inferred distribution, trend, and day-night difference of the features detected. Thus, maps/distributions as well as long-term variations of the measurement noise can provide a valuable diagnosis in interpreting the patterns and changes of detected features. Some discussions on false detection and misclassification of feature detection with the CALIOP data can be found in Liu et al. (2006) and Vaughan et al. (2009). CALIOP instrument calibration and performance can be found in Hunt et al. (2009).

In this study we will carry out further analyses on noise characteristics of the calibrated CALIOP backscatter (Level 1, or L1) data in the provisional release (versions 2.01 and 2.02), and evaluate impacts of these noise properties on feature detection (e.g., clouds and aerosols). Through a better understanding and characterization of the CALIOP measurement noise, we hope to apply our research algorithm for joint analyses of CALIOP and other A-train observations (e.g., Aura MLS) in UT/LS cloud/aerosol studies. To achieve this goal, we first reduce the L1 CALIOP data to a manageable size by aggregating them to a coarser spatial resolution, and estimate the measurement noise in terms of mean $(\mu)$ and standard deviation $(\sigma)$. We then study features in the aggregated data using the research algorithm with various threshold schemes to gain more insights about measurement noise effects. The derived atmospheric features are often referred as to Level 2 (L2) products. Some of the initial results for noise evaluation and feature detection with the v2.01 and v2.02 CALIOP L1 and L2 data at $5 \mathrm{~km}$ horizontal resolution are presented here.

\section{Data and methods}

For the CALIOP L1 data, we use the provisional release (v2.01 and v2.02) of the attenuated backscatter coefficients in $\mathrm{km}^{-1} \mathrm{sr}^{-1}, \beta^{\prime}(z)$, of total (TOT) and perpendicularpolarization (PER) signals at 532 and $1064 \mathrm{~nm}$. The L1 files also contain auxiliary data such as molecular and ozone density profiles provided by NASA's GMAO (Global Modeling and Assimilation Office), which are needed for estimating the molecular scatter background. The original L1 data have 583 vertical levels with resolutions from $30 \mathrm{~m}$ near the surface to $300 \mathrm{~m}$ in the stratosphere, and horizontal resolution of $300 \mathrm{~m}$ [Winker et al., 2009]. To reduce the data file size to a manageable volume, we aggregate the data vertically (194 levels) and horizontally $(5 \mathrm{~km})$. The vertical resolutions of the aggregated $\mathrm{L} 1$ data become $90 \mathrm{~m}$ at $-0.5-8.2 \mathrm{~km}, 180 \mathrm{~m}$ at $8.2-20.2 \mathrm{~km}, 540 \mathrm{~m}$ at $20.2-30.1 \mathrm{~km}$, and $900 \mathrm{~m}$ above $30.1 \mathrm{~km}$; and the horizontal resolution, originally $300 \mathrm{~m}$, becomes $5 \mathrm{~km}$. The non-uniform vertical resolution will be factored as the weighted measurement error in our analysis because of different integration time (e.g., Liu et al., 2006).

For the CALIPSO L 2 layer products (i.e., $05 \mathrm{~km}$ _CLay and $05 \mathrm{~km} \_$ALay), we use only the features detected at the $5-\mathrm{km}$ horizontal resolution. The CALIPSO L2 algorithm employs a detection scheme with variable horizontal lengths on the attenuated total 532-nm backscatter (Vaughan et al., 2009). By taking advantage of feature signal strength and spatial correlation, the L2 algorithm is able to detect weak features, such as thin cirrus, polar stratospheric clouds (PSCs), and aerosol layers, using an adaptive multi-profile averaging scheme to search for coherent features in consecutive profiles within 5,20 , and $80 \mathrm{~km}$ in distance. It starts a feature search with the 80-km window along track, and then proceeds the searching with the $20-\mathrm{km}$ and $5-\mathrm{km}$ window. Each detected cloud/aerosol feature is associated with a flag that contains information on the searching window size(s) whereby the feature was obtained. In the L2 algorithm the detected cloud/aerosol layers must meet a requirement for minimum thickness.

In Fig. 1 are two examples of the attenuated backscatter profiles from the CALIOP L1 data. The clear-sky backscatters should be close to the molecular scattering background (solid line) if measurement noise is small. However, most of the data points scattered around this background is due to noise, and those outstanding positive outliers (e.g., in the nighttime profiles) are cloud/aerosol features. In the nighttime 532-nm TOT profile, the sharply reduced backscatters at altitudes $<\sim 5 \mathrm{~km}$ are due to strong attenuation of a cloud layer at $\sim 5 \mathrm{~km}$. The backscatter measurements are generally noisier at lower altitudes primarily because of the finer vertical bins (i.e., less integration time per bin), and the daytime measurements are generally noisier than nighttime data due to additional background scattering from sunlight. The molecular scattering background can be seen clearly in the bottom of 532-nm TOT data, but barely in the 1064-nm 

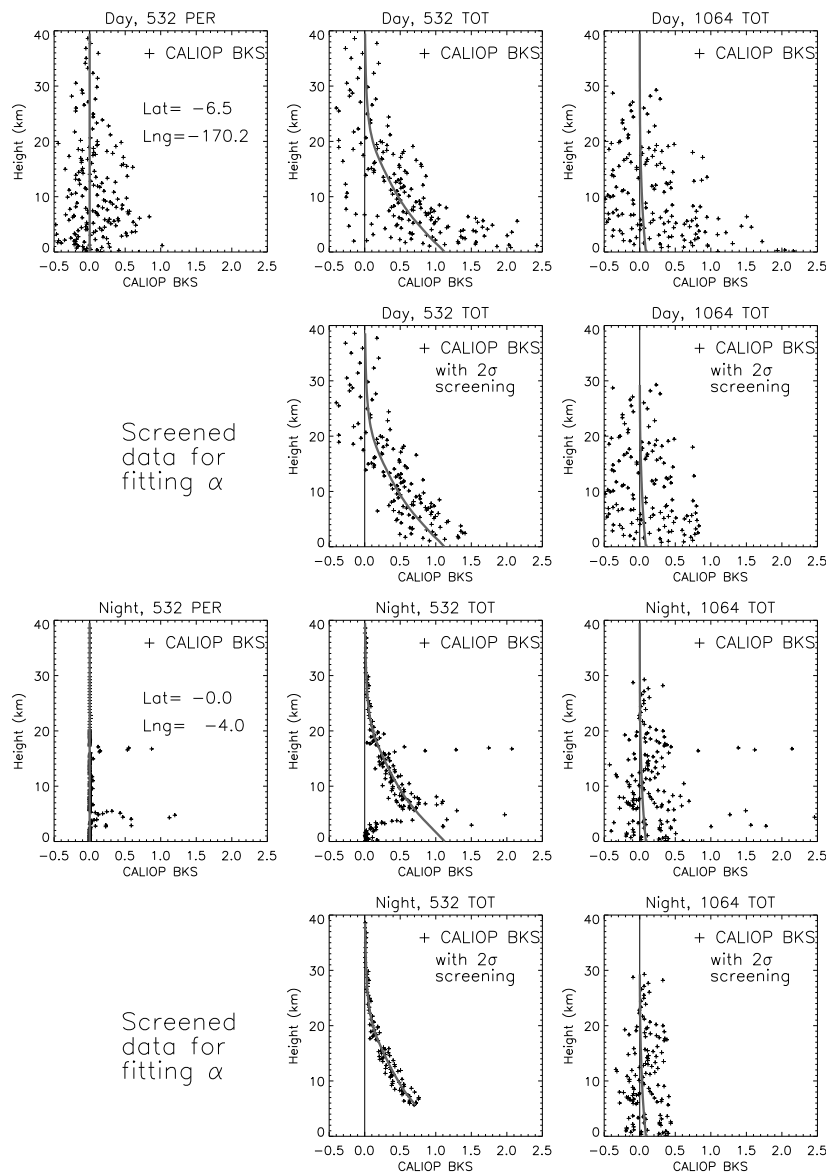

Fig. 1. Attenuated CALIOP backscatter profiles (in $10^{-3} \mathrm{~km}^{-1} \mathrm{sr}^{-1}$ ) for a tropical daytime (top two panels) and nighttime (bottom two panels) case on 1 January 2008. The thick grey curve is the background molecular backscatter profile estimated from the atmosphere density data provided in the Level 1 file. For fitting the scaling factor $\alpha$, the data are screened with a $2 \sigma$ rejection method to remove outliers due to cloud/aerosol (see text), and the retained data are shown in the panel below the original profiles. There are no 1064-nm backscatter data at heights above $\sim 30 \mathrm{~km}$.

profiles. Measurement noise is smaller in the 532-nm PER data with little molecular scattering, but the cloud/aerosol signals in this channel are also weaker. The daytime 1064$\mathrm{nm}$ and 532-nm TOT noise is similar, but in nighttime the 1064-nm data are noisier than 532-nm.

For each backscatter profile, the clear-sky molecular scatter profile, $\beta_{\mathrm{w}}(z)$, is estimated using the atmospheric variables (e.g., air and ozone number density profiles) provided in the CALIOP L1 file. To mimic the lidar measurement, it is further attenuated by the two-way molecular and ozone transmission $T_{\mathrm{mol}}^{2}$ and $T_{\mathrm{o} 3}^{2}$, namely, $\beta_{\mathrm{w}}(z) T_{\mathrm{mol}}^{2} T_{\mathrm{o} 3}^{2}$, as described in the CALIPSO algorithm theoretical basis document [Hostetler et al., 2006]. This modeled molecular scatter profile can be used to verify the calibrated clear-sky lidar backscatters. Imperfectly calibrated backscatter data may be detectable when compared to the modeled molecular background. For the 532-nm channel, the current calibration relies on primarily on nighttime data and assumes no aerosol at altitudes between $30-34 \mathrm{~km}$. As revealed in Vernier et al. (2009), the presence of stratospheric aerosols may account for $5-12 \%$ of error on the calibration coefficient. To investigate potential error in the calibrated backscatters, for each profile we fit the clear-sky portion of the data to the modeled molecular profile, $\alpha \cdot \beta_{\mathrm{w}}(z) T_{\mathrm{mol}}^{2} T_{\mathrm{o} 3}^{2}$, with a scaling factor $\alpha$. For the perfect clear-sky atmosphere (i.e., free from aerosol and cloud) and perfectly calibrated data, the fitting should yield $\alpha=1$.

In the $\alpha$ calculation, the key is to obtain the clear-sky data points for each profile by screening out cloud/aerosol data points as well as those measurements affected by their attenuation. However, this is not trivial because of large fluctuations in the lidar backscatters. We employ the iterative approach used in CloudSat data for the clear-sky screening (Tanelli et al., 2008; Wu et al., 2009), except in the CALIOP case the clear-sky molecular background is a profile. The procedure for obtaining the "clear-sky" profile with the screening-and-fitting iteration is as follows. We first exclude those profiles if any atmospheric value of the 532-nm TOT backscatter exceeds $0.004 \mathrm{~km}^{-1} \mathrm{sr}^{-1}$, for which an atmospheric measurement is one at an altitude at least $400 \mathrm{~m}$ above the surface. This initial screening helps to eliminate the profiles with strong cloud scattering. For the remaining profiles, we further screen them to minimize cloud/aerosol contamination. We start with the modeled molecular profile $\beta_{\mathrm{w}}(z) T_{\mathrm{mol}}^{2} T_{\mathrm{o} 3}^{2}$ and subtract it from the observed backscatter profile $\beta$ ' $(z)$. The difference, i.e., $\Delta \beta(z)$ $=\beta^{\prime}(z)-\beta_{0}(z) T_{\mathrm{mol}}^{2} T_{\mathrm{o} 3}^{2}$, which may contain cloud/aerosol features (positive values) and strongly-attenuated backscatter (negative values) as seen in Fig. 1, is further screened by a so-called $2 \sigma$ rule. According to this rule, those points that are $>2 \sigma$ away from the estimated molecular background on both sides will be rejected as spikes. From the remaining $\Delta \beta(z)$ as illustrated in Fig. 1, the mean and standard deviation ( $\mu$ and $\sigma$ ), as well as the scaling factor $\alpha$, are calculated. Note that scaling factor $\alpha$ and $\mu$ are related through $\mu$ $\equiv<\Delta \beta(z)>=(\alpha-1)<\beta_{0}(z) T_{\mathrm{mol}}^{2} T_{\mathrm{o} 3}^{2}>$, where \langle\rangle is the vertical average weighted by the estimated measurement error profile. The above screening-fitting procedures are repeated for several times in order to improve the estimate values for $\mu, \sigma$, and $\alpha$. Convergence (i.e., negligible change) is usually achieved within 3-4 iterations, and non-convergent cases are discarded. For each iteration, we replace $\Delta \beta(z)$ with $\beta^{\prime}(z)$ $\alpha \cdot \beta_{0}(z) T_{\mathrm{mol}}^{2} T_{\mathrm{o} 3}^{2}$ and use it for calculating the new $\mu$ and $\sigma$ before the next screening-fitting. The final $\mu, \sigma$ and $\alpha$ are output as the measurement error for this profile. If the number of remaining data points in the last iteration is less than 100 , the profile is discarded as well. We have applied the same screening-fitting procedure for CALIOP 532-nm and 1064-nm TOT data. 

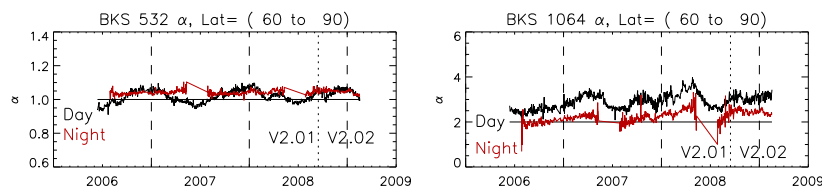

$\operatorname{BKS} 532 \alpha$, Lat $=(30$ to 60$)$

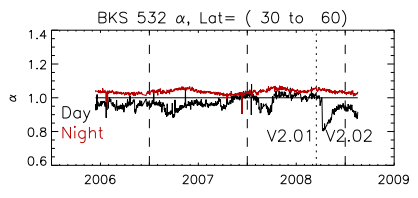

BKS $1064 \alpha, \mathrm{La}^{*}=(30$ to 60$)$

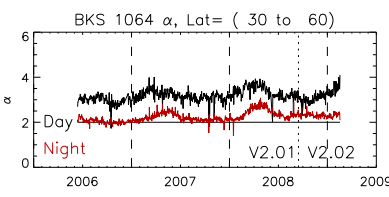

BKS $532 \alpha$, Lat $=(0$ to 30$)$
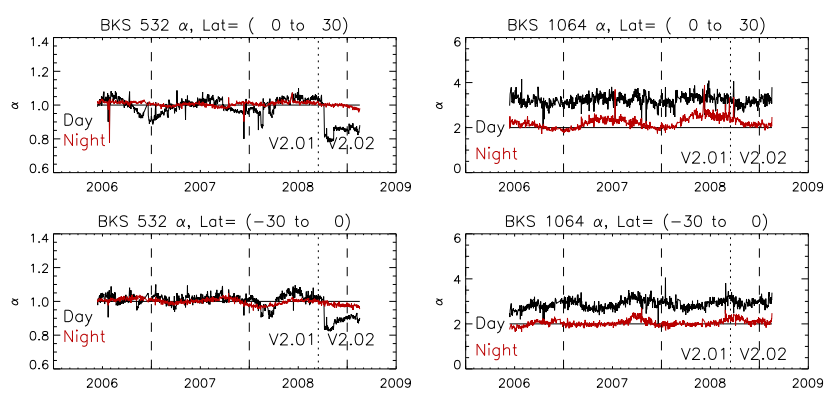

BKS $532 \alpha$, Lat $=(-60$ to -30$)$

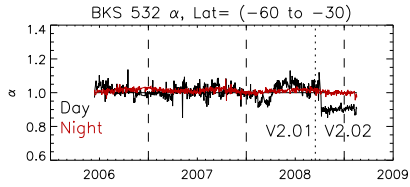

BKS $532 a$, Lat $=(-90$ to -60$)$
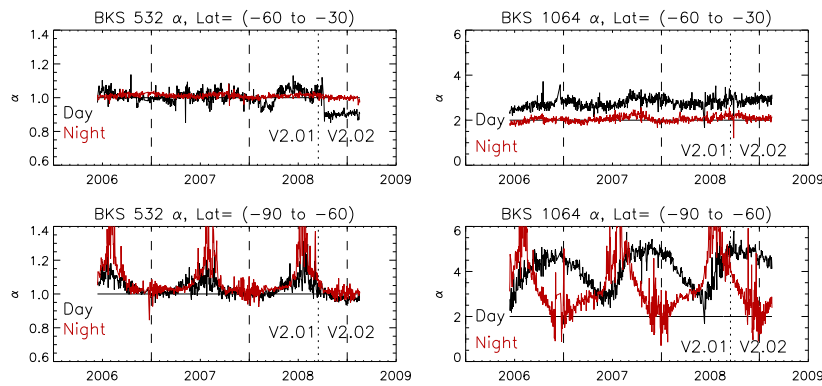

BKS $1064 \alpha$, Lat $=(-90$ to -60$)$

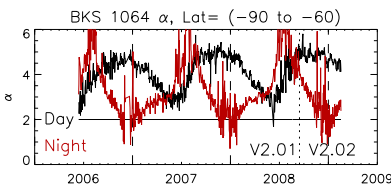

Fig. 2. Time series of daily mean $\alpha$, the ratio of estimated vs. modeled clear-sky molecular backscatter, averaged into six latitude bins for day (black) and night (red) data at 532-nm (left) and 1064-nm (right) channels. The reference of $\alpha=1$ and $\alpha=2$ are provided respectively for the 532-nm and 1064-nm channels to guide comparison. Since individual $\alpha$ values vary substantially due to measurement noise, large spikes ( $|\alpha|>5$ for 532-nm, $|\alpha|>10$ for 1064-nm) are excluded in the daily mean calculations. The year boundary is indicated by dashed lines, whereas the dotted line marks the version change from v2.01 to v2.02.

To monitor the calibrated CALIOP backscatters using the modeled molecular background, we compute daily mean $\alpha$ of the 532-nm and 1064-nm data, and present the day and night series separately in Fig. 2. The estimated $\alpha$ values are sensitive to errors in instrument calibration as well as in the model atmospheric variables (e.g., pressure, ozone density, and stratospheric aerosols). Because these errors may depend on latitude, we divide the daily mean $\alpha$ into six latitude bins. As shown in Fig. 2, the nighttime 532-nm $\alpha$ values at low and middle latitudes are close to unity with only small $(<5 \%)$ variability. However, $\alpha$ exhibits a larger seasonal variation at high latitudes, especially in the Southern Hemisphere (SH), of which the larger 532-nm $\alpha$ values in the $\mathrm{SH}$ summer are due to PSC contamination in the fitted $\alpha$. Compared to the nighttime values, the daytime 532-nm $\alpha$ values are noisier with a larger $(<10 \%)$ seasonal variation, which is expected for the noisier backscatter measurements. A large $(\sim 10 \%)$ drop in the daytime $\alpha$ occurred around 6 October 2008 , which is not associated with the version change from v2.01 to v2.02. The fact that the drop occurred only in the daytime data suggests that it was not caused by error in the atmosphere model. Thus, the drop likely reveals a calibration change in the daytime data. Beside the larger seasonal variation, the daytime 532-nm $\alpha$ values before October 2008 are generally around unity, in line with the nighttime values, except at the $30^{\circ} \mathrm{N}-60^{\circ} \mathrm{N}$ bin where the daytime values are lower by $5-10 \%$.

We also evaluate the new version (v3.01) CALIOP data using the same algorithm [not shown], and no sharp drop in the daytime 532-nm $\alpha$ is found during this period of time, confirming that this calibration error is in the v2 data. The morphology of $\mu$ and $\sigma$ estimated from the $\mathrm{v} 3.01$ data is similar to what is shown here for the v2 data. The derived nighttime 532-nm $\alpha$ is close to unity in the tropics with slightly larger seasonal variations. The daytime 532-nm $\alpha$ are generally lower than the nighttime values by $0.05-0.1$ in the tropics.

Unlike in the 532-nm case, it is more challenging to fit the 1064-nm molecular scatter background, not only because the measurement is noisier but also because the molecular background profile is $\sim 16 \times$ weaker. As seen in Fig.2, the derived $\alpha$ values vary generally between 2 and 3 , and the noisier day values are systematically higher than the night. At low and middle latitudes both day and night series reveal a comparable seasonal variation. There appears a slight increasing trend in the nighttime $\alpha$ at these latitudes. To evaluate how the fitted $\alpha$ depends on the $\sigma$-based screeningfitting approach, we tried the $\alpha$ fitting with different multiples of the $\sigma$-value for the "clear-sky" screening, and found that the derived $\alpha$ values would decrease slightly associated with a slight increase in seasonal variability. The increase in seasonal variability can be explained by more cloud/aerosol contamination in loosening the screening criteria. This is detailed further in the following.

It is not trivial to extract "clear-sky" atmospheric molecular background from the noisy data. In addition to the measurement noise, cloud/aerosol features (above the atmospheric molecular background) and attenuated values (below the background) in the data, as shown in Fig. 1, can be challenging to screen. We tested various noise thresholds (from $1 \sigma$ to $50 \sigma$ ) for screening the outliers, and found that the $2 \sigma$ approach produces the best results in terms of minimizing daily and seasonal fluctuations. Since the cloud/aerosol contamination would manifest itself with a significant seasonal variation, minimizing the seasonal variability for the derived $\alpha$ values is necessary for the reliable $\alpha$ estimation. The $1 \sigma$ approach would leave too few data points for the fitting. On the other hand, with a larger (looser) threshold, the contaminations from cloud/aerosol features and attenuated values would tend to bias the fitted $\alpha$ values. 
The scaling $\alpha$ approach has demonstrated some promising capabilities in monitoring and diagnosing trends and abrupt changes in the calibrated CALIOP backscatter data. It can be further refined to produce more robust results with less dependence on the screening for "clear-sky". For example, the screening-fitting can be restricted to middle-to-high altitudes or certain latitudinal/geographical areas where cloud/aerosol contributions are smaller and have low occurrence. Also, it might be limited to the oceanic regions where the measurement noise is low. Nevertheless, more dedicated investigations are needed to improve the method by better understanding the latitudinal and seasonal variations seen in the estimated $\alpha$ values.

Because the estimated $\alpha$ values are noisy and can be affected by both measurement and model errors, which are non-trivial to distinguish at this point, in the analysis hereafter we ignore the seasonal variations in the fitted $\alpha$ and use $\alpha=1.0$ to remove the background molecular backscatter to compare the feature detection from this work with the L2 layer products. In the subsequent analyses, the $\mu$ and $\sigma$ of the measurement noise are estimated from $\Delta \beta(z)$ only at $z>19 \mathrm{~km}$.

\section{Morphology of CALIOP backscatter noise}

The CALIOP backscatter measurement noise has highdegree transiency, varying largely from profile to profile. This is evident in the $\sigma$ estimated from the data at $z>19 \mathrm{~km}$ (Fig. 3). The large $\sigma$ variation can affect the cloud/aerosol detection throughout a backscatter profile. The $\mu$ value of the measurement error is usually smaller than $\sigma$. As shown in Fig. 3, the nighttime 532-nm PER $\sigma$ values are much lower than other cases, which could yield a higher signalto-noise ratio (SNR) for weak cloud/aerosol signals if these features produce a significant depolarization ratio. The flat noise floors in the nighttime noise reflect the detector noise, whereas large fluctuations in the daytime noise are indicative of the additive photon noise from bright objects. The low nighttime $\sigma$ makes additional noise sources stand out, which would not be able to be seen otherwise. For examples, the dark count increases in the radiation-hard regions, such as the South Atlantic Anomaly (SAA) and auroral ovals, are evident in this orbit [Hunt et al., 2009]. Unlike the 532$\mathrm{nm}$ measurements, the 1064-nm backscatters do not exhibit obvious dependence on the SAA because the $532 \mathrm{~nm}$ detectors are photomultiplier tubes (PMTs) and more susceptible to radiation effects than the $1064 \mathrm{~nm}$ avalanche photodiodes (APDs). As discussed in Hunt et al. (2009), PMTs have modest quantum efficiencies with relatively low dark noise that should obey the Poisson statistics, whereas APDs have high quantum efficiencies but with high Gaussian-like dark noise.

To characterize the CALIOP backscatter noise distribution, which can affect the distribution of feature detectability, we map the monthly-mean $\mu$ and $\sigma$ separately for day

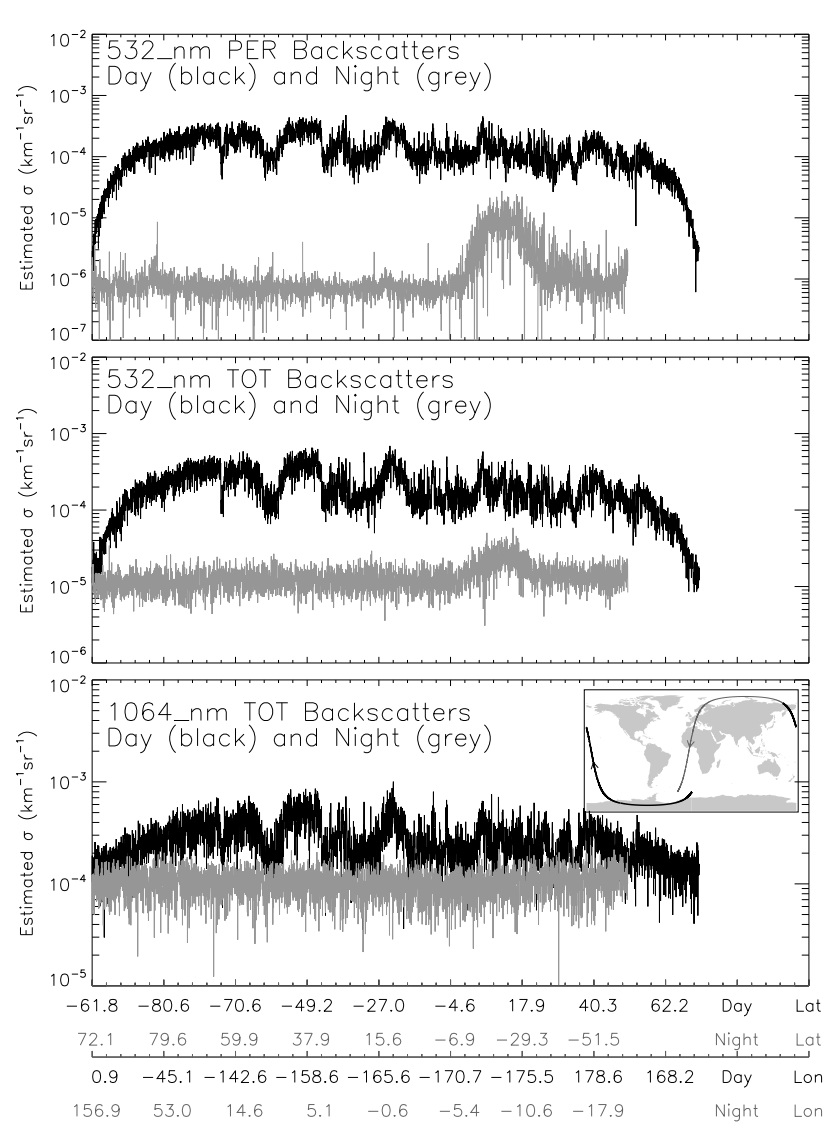

Fig. 3. Orbital variations of the estimated $\sigma$ of the 532-nm PER (top), 532-nm TOT (middle), and 1064-nm TOT (bottom) backscatter from an orbit (embedded map) on 1 January 2008. The A-Train orbit has a $98^{\circ}$ inclination angle and the flight direction is indicated by the arrows on the map. The day (night) portion of the orbit is depicted by black (grey) line. The nighttime 532-nm noises reveal higher $\sigma$ values at latitudes of $\sim 30^{\circ} \mathrm{S}$ due to the South Atlantic Anomaly (SAA).

and night. January 2008 is chosen to illustrate the derived noise properties, but other months reveal similar characteristics. Unlike the nighttime, the daytime CALIOP backscatter noise is dominated by the background scattering sunlight, which is additive and Gaussian-like. It is highly variable depending on surface/atmospheric albedo. The daytime $\mu$ (Fig. 4) is nearly zero globally for all the CALIOP channels, except in the SAA region where it is slightly negative in the 532-nm PER and TOT data. However, the $\sigma$ values vary highly with surface and cloud albedo. The albedo effects appear to modulate the 532-nm $\sigma$ by a factor of $2-$ 5 (higher in cloudy/snowy/icy regions) or over landmasses (e.g., desert). Compared to the 532-nm measurements, the 1064-nm $\sigma$ map shows more distinct contrast between land and ocean mostly in the SH. The nighttime $\mu$ and $\sigma$ values (Fig. 5), although generally lower than the daytime, reveals features related to the detector response to radiationhard (e.g., SAA, high-latitude geomagnetic activities). These 

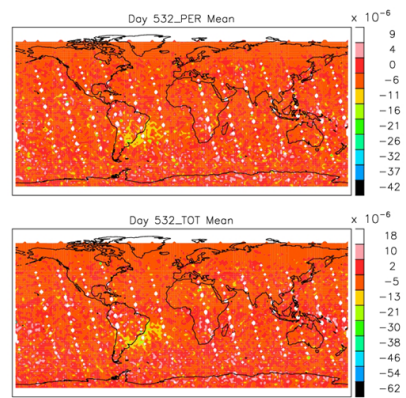

Day 1064_ToT Mean
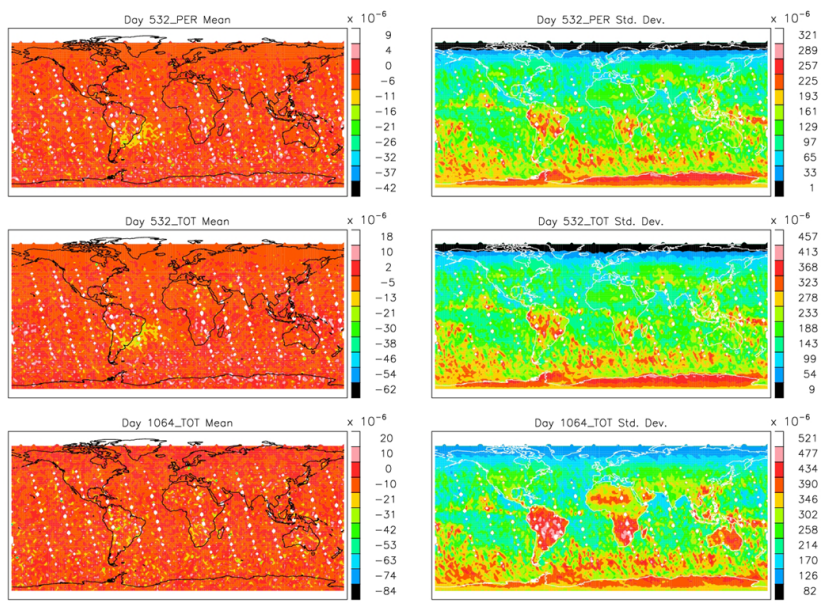

Fig. 4. Monthly (January 2008) mean $\mu$ and $\sigma$ maps of daytime 532-nm PER (top), 532-nm TOT (middle), and 1064-nm TOT (bottom) backscatter noise (in $\mathrm{km}^{-1} \mathrm{sr}^{-1}$ ) on a $2^{\circ} \times 2^{\circ}$ longitudelatitude grid. Most part of the daytime orbits is ascending (i.e., latitude increasing with time). The descending portion of the orbits is excluded to minimize the mixed statistics between the two local times.

geomagnetic features are more pronounced in the 532-nm than in the 1064-nm measurements. The 532-nm PER and TOT are respectively $\sim 50 \times$ and $\sim 5 \times$ less noisy than the measurements in the geomagnetic-active regions. The radiation-induced dark counts in PMT become only important during nighttime when the solar background noise is absent.

Although $\sigma$ from altitudes $>19 \mathrm{~km}$ provides the first-order estimate of the lidar measurement noise, it is also useful to examine noise properties as a function of height, because additional measurement error might appear at different altitudes. If the $\sigma$ estimated from altitudes $>19 \mathrm{~km}$ can represent the noise well for each profile, one may apply a uniform $\sigma$-based threshold to the entire profile for feature detection. More complete statistical properties of the CALIOP noises are presented in Figs. 6-8 in terms of the normalized probability density function (PDF). The PDF is normalized in the way such that its integration (i.e., the area under each curve) is unity. For the noisy data where signal and noise have a comparable probability (or weak signals), the normalized PDF provides a powerful means to evaluate the subtle differences between two data sets (e.g., day-night differences) without imposing a clear-cut detecting threshold ( $\mathrm{Wu}$ et al., 2009). The PDFs in Figs. 6-8 are derived from the attenuated backscatters with the molecular background subtracted. The number of samples in each backscatter value bin is first divided by the total number for normalization and then by the bin sizes to yield probability density. Since cloud/aerosol scatterings often produce positive backscatters at most of these altitudes, the negative PDF domain reflects characteristics of the measurement noise, which can
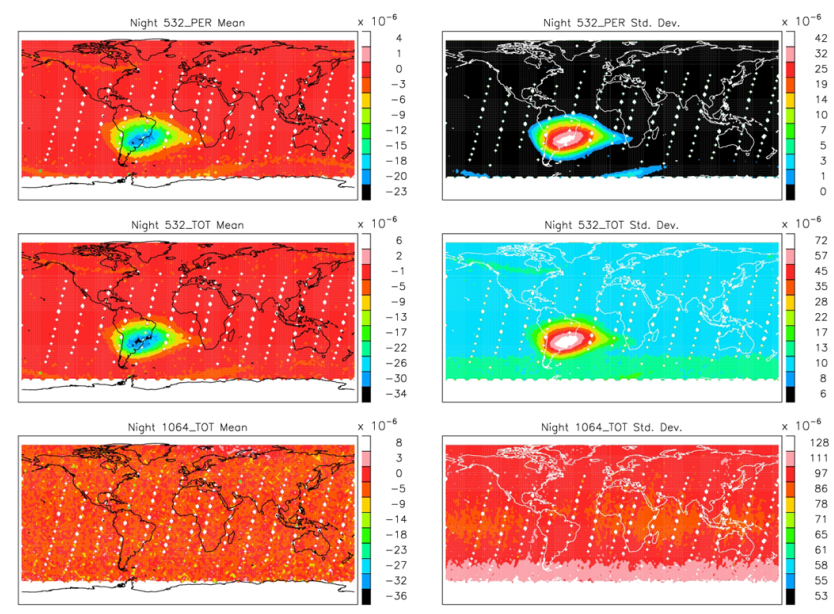

Fig. 5. As in Fig. 4 but for the nighttime backscatter noise, and the ascending portion of the orbits is excluded.

be Gaussian or non-Gaussian depending on noise sources. However, clouds/aerosols also attenuate the molecular background scattering below them, which could skew the negative PDF domain. This effect is evident in the nighttime 532-nm data at lower altitudes.

The rising portion of PDF at small values in Figs. 6-8 is indicative of the measurement noise. For the noise with zero mean, the positive and negative PDF domains should yield a consistent distribution in the noise portion of PDF. Hence, we fold the negative PDF domain to the positive side for comparison. In the case where measurements are dominated by the measurement noise (usually at altitudes $>19 \mathrm{~km}$ ), the positive and negative PDF domains overlap, as seen in Figs. 6-8 at $21.7 \mathrm{~km}$. In the presence of clouds/aerosols, the positive PDF domain will deviate from the negative one, showing an extended distribution at large values. The estimated $\sigma$ shows a slight increase with decreasing altitude, which is expected for the increasing vertical resolution (or decreasing measurement integration time) at lower altitudes. No significant additional noise source is added to the $\sigma$ estimated from altitudes $>19 \mathrm{~km}$, and therefore the $\sigma$-based threshold for feature detection can be applied to the entire profile. Some of the measurement noise may not be Gaussian, as seen in the nighttime 532-nm data (Fig. 6). Non-Gaussian or multi-Gaussian cases require special care for cloud/aerosol detection, because feature detection from the $\sigma$-based method could encounter a higher false-positive rate than what it produces with the Gaussian case.

For feature detection in this study, a conservative threshold ( $>5 \sigma$ is applied to the daytime data on a profile-byprofile basis (Table 1), which would yield a very small (1 out of 1.7 million) false detection rate if the measurement noise is Gaussian. For the nighttime data, however, different thresholds are used. As seen in Fig. 6, the nighttime 532-nm PER data have complicated noise characteristics when the measurements are associated with very low 

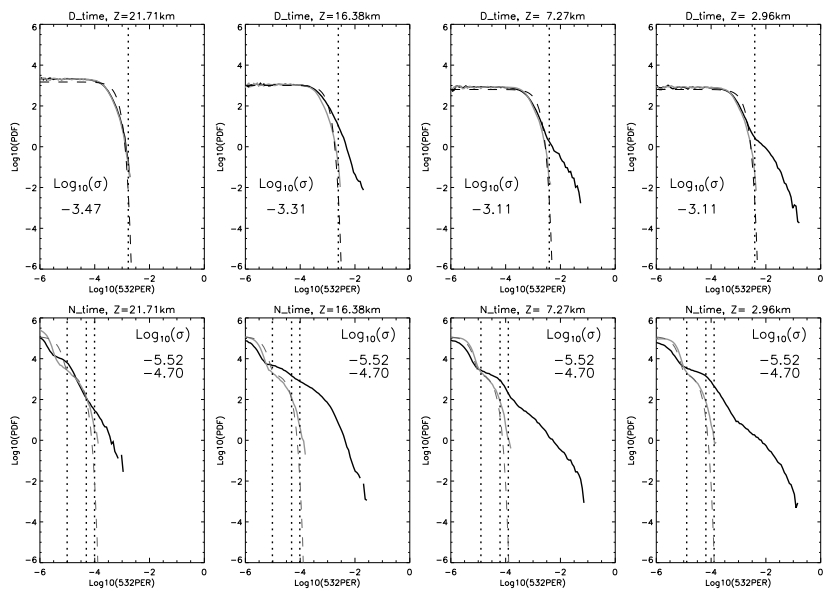

Fig. 6. Normalized PDFs of the attenuated 532-nm PER backscatter for a tropical $\left(10^{\circ} \mathrm{S}-10^{\circ} \mathrm{N}\right)$ bin in January 2008. The PDF is normalized such that its integration over all backscatter bins is equal to unity. The $\sigma$ values estimated from the negative PDF domain for daytime (upper panels) and nighttime (lower panels) are given in each panel. For the 532-nm PER measurement, the nighttime noise is composed of two Gaussian functions with the $\sigma$ values shown in each panel. Vertical dotted lines indicate the $5 \sigma$ value for day, and $1 \sigma, 5 \sigma$, and $10 \sigma$ for night. The grey curve is the negative PDF domain folded onto the positive side to evaluate the CALIOP noise. The dashed line is the analytical Gaussian function for the estimated $\sigma$. All PDFs are plotted in a log-log scale with backscatter in $\mathrm{km}^{-1} \mathrm{sr}^{-1}$ and PDF in $\mathrm{km}$ sr. The SAA contribution is excluded in the statistics at this latitude bin.
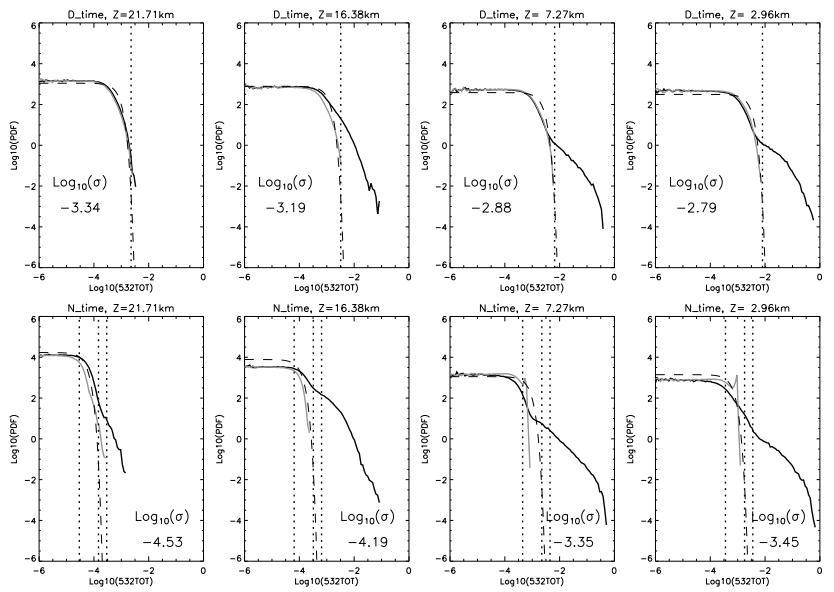

Fig. 7. As in Fig. 6 but for the 532-nm TOT backscatter. The sharp cutoff in the negative PDF domain of the nighttime data (at 2.96 and $7.27 \mathrm{~km}$ ) results from cloud/aerosol attenuation.

photon counts. Non-Gaussian or multi-Gaussian noise become important for backscatter values $<10 \sigma$. Part of the second Gaussian with a higher $\sigma$ galue is due to contributions from the SAA because this tropical bin $\left(10^{\circ} \mathrm{S}-10^{\circ} \mathrm{N}\right)$ retains a small portion of the SAA. We find that the second
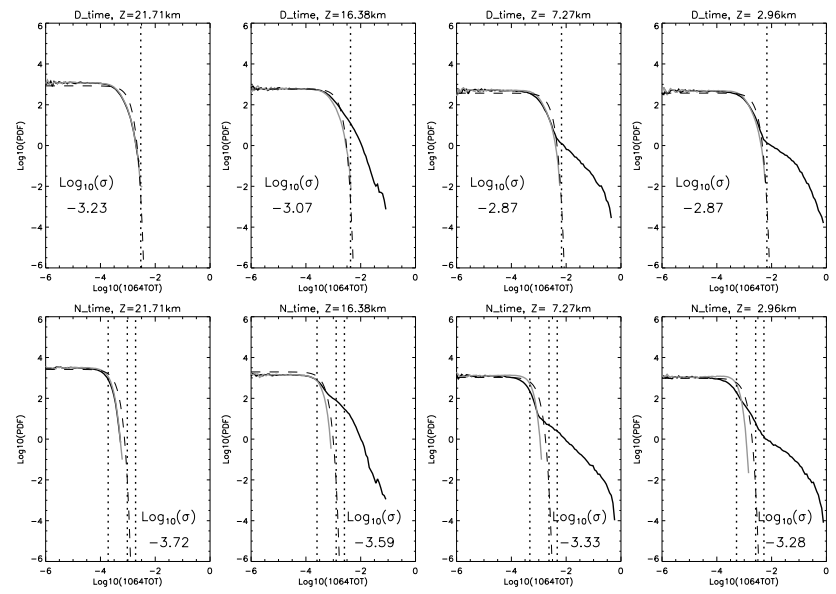

Fig. 8. As in Fig. 6 but for the 1064-nm TOT backscatter.

Gaussian noise is still present but significantly reduced in the statistics of the equator- $20^{\circ} \mathrm{N}$ bin. Because of this multiGaussian noise character, a higher $(>80 \sigma)$ threshold is used for the cloud/aerosol detection with the nighttime 532-nm PER data. For the 532-nm TOT data (Fig. 7), the negative and positive PDF domains agree well with each other in the noise portion. Unlike the 532-nm PER case, the nighttime 532-nm TOT PDFs are mostly single-Gaussian. Although stratospheric aerosols are difficult to detect, their contributions can be inferred from differences between the PDFs of positive- and negative-value backscatters at night. For example, at $21.7 \mathrm{~km}$ the positive PDF domain extends above the negative one, suggesting potential contributions from stratospheric aerosols. At lower altitudes the negative-value PDF can rise above the positive-value one because there exist a significant number of attenuated backscatter cases. In these situations, the backscatters beneath cloud/aerosol layers are severely attenuated such that these values can fall below the estimated molecular scattering background, resulting in negative $\Delta \beta(z)$ values. This attenuation effect is more evident in the PDFs from the night data than from the day.

A significant change in the PDF slope is evident in the nighttime data at $16.4 \mathrm{~km}$ (Figs. 6-7), which occurs at the values of $\sim 10^{-2.5} \mathrm{~km}^{-1} \mathrm{sr}^{-1}$. This PDF property is beyond detection by the daytime measurements. The attenuation is unlikely the cause of this slope transition since it is observed at all altitudes between 14 and $18 \mathrm{~km}$. The PDF slope between the values of $10^{-3.5}$ and $10^{-2.5} \mathrm{~km}^{-1} \mathrm{sr}^{-1}$ is similar to those observed at a lower altitudes, while the one at values greater than $10^{-2.5} \mathrm{~km}^{-1} \mathrm{sr}^{-1}$ is much steeper, indicating lack of sources for these clouds.

The 1064-nm data bear many similarities to the 532-nm TOT results in terms of PDF characteristics, except for a slightly higher $\sigma$ (Fig. 8). Unlike the 532-nm data, the nighttime 1064-nm data do not have a spike in the negative PDF domain at lower altitudes because the molecular scattering background is $\sim 16 \times$ weaker at $1064 \mathrm{~nm}$. 
Table 1. Cloud/Aerosol detection thresholds (in $\mathrm{km}^{-1} \mathrm{sr}^{-1}$ ) used in this study.

\begin{tabular}{llll}
\hline & 532-nm PER & 532-nm TOT & 1064-nm TOT \\
\hline Daytime & $\operatorname{Min}\left(5 \sigma, 1 \times 10^{-4}\right)$ & $\operatorname{Min}\left(5 \sigma, 1 \times 10^{-4}\right)$ & $\operatorname{Min}\left(5 \sigma, 1 \times 10^{-3}\right)$ \\
Nightime & $\operatorname{Max}\left(80 \sigma, 3 \times 10^{-4}\right)$ & $\operatorname{Max}\left(16 \sigma, 3 \times 10^{-4}\right)$ & $\operatorname{Max}\left(8 \sigma, 3 \times 10^{-4}\right)$ \\
\hline
\end{tabular}
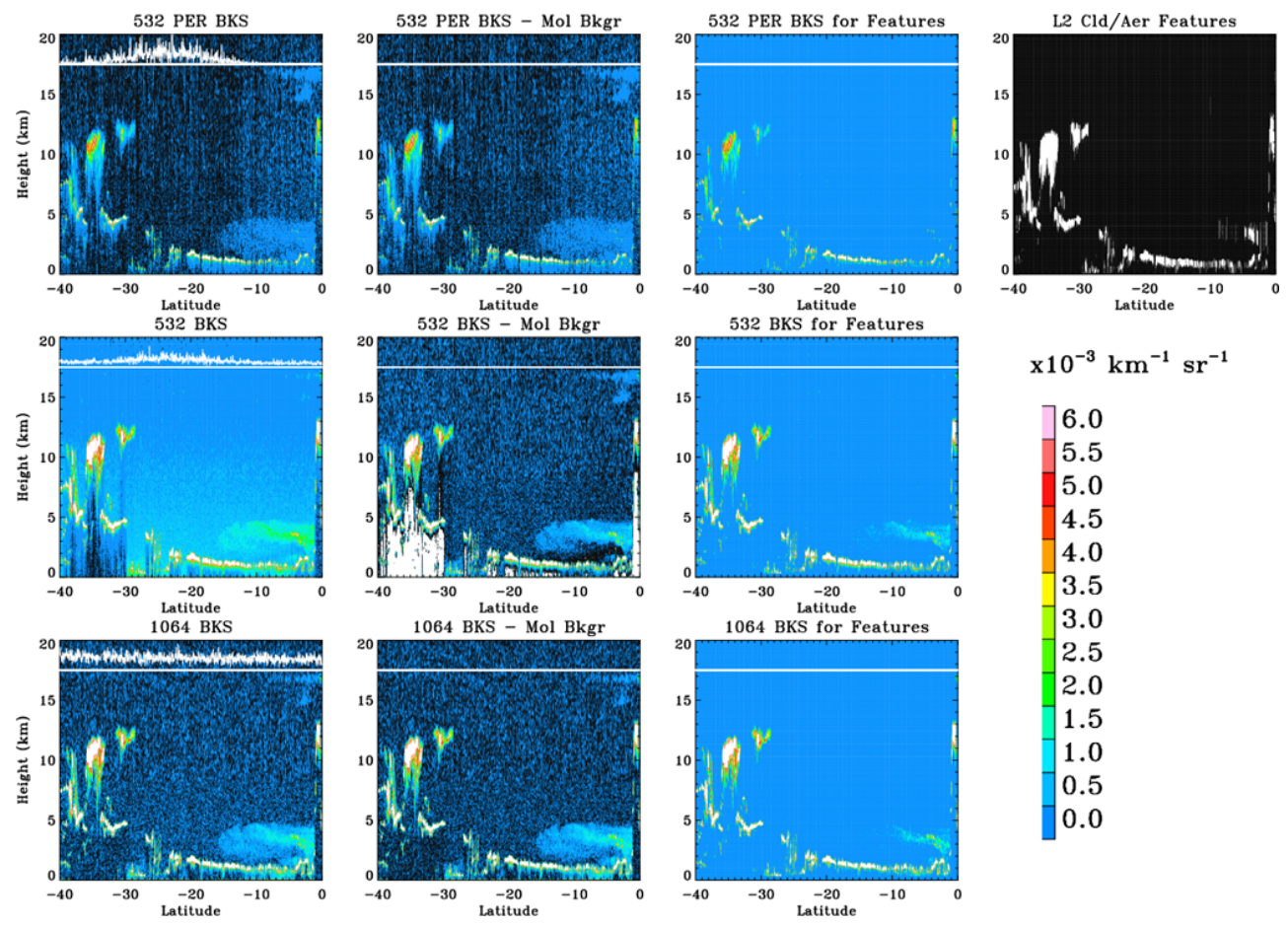

Fig. 9. From left to right: Examples of the nighttime total attenuated 532 and 1064 backscatters from 1 January 2008 (the same orbit as in Fig. 3); the backscatters with the molecular background removed; the features identified with the $\sigma$ thresholds in Table 1; and the feature detected in the L2 products. The curve at the top of each left panel is the same measurement noise $\sigma$ as shown in Fig. 3 to illustrate relative changes in noise.

\section{Implications for feature detection}

For feature detection, we tested a range of the $\sigma$ threshold with the $\sigma$-based method, and the thresholds listed in Table 1 produce the results similar to the L $205 \mathrm{~km}$-CLay and $05 \mathrm{~km} \_$ALay products. These thresholds ( $5 \sigma$ or greater) allow us to aggressively exclude the clear-sky background noise with a low false-positive rate for both Gaussian and non-Gaussian noise cases. The false-positive rate can be estimated from the stratospheric measurements where cloud/aerosol features have a very low occurrence frequency. To prevent the threshold from reaching too high or too low, we amended the $\sigma$-based detection rule with a maximum/minimum bound (Table 1). In addition, we also require that a feature must appear in two or more consecutive vertical bins. This additional requirement further reduces the false-positive error, which helps the cloud detection near the tropopause where cloud occurrence frequency drops sharply with height. Because the $\sigma$ value used for feature detection is estimated on a profile-by-profile basis, the region with a higher $\sigma$, such as the SAA and landmasses, will inevitably have poorer detecting ability, leading to potential sampling artifacts in the observed cloud/aerosol pattern.

The $\sigma$-based feature detection has less impact on the pattern or time series of feature backscatter than on feature occurrence frequency. Since small values do not contribute much to the average backscatter, the pattern or time series associated with feature backscatter is not very sensitive to the threshold used. However, feature occurrence frequency is sensitive to the threshold used. Figure 9 compares some examples of the features detected by the research algorithm and the $\mathrm{L} 2$ algorithm. The algorithm using the Table 1 thresholds may reject some of the tenure aerosol and cirrus features in the scene. To study weak stratospheric aerosol features, one may need to lower the values used in Table 1 for aggressive detection. The thresholds may have to be modified if 

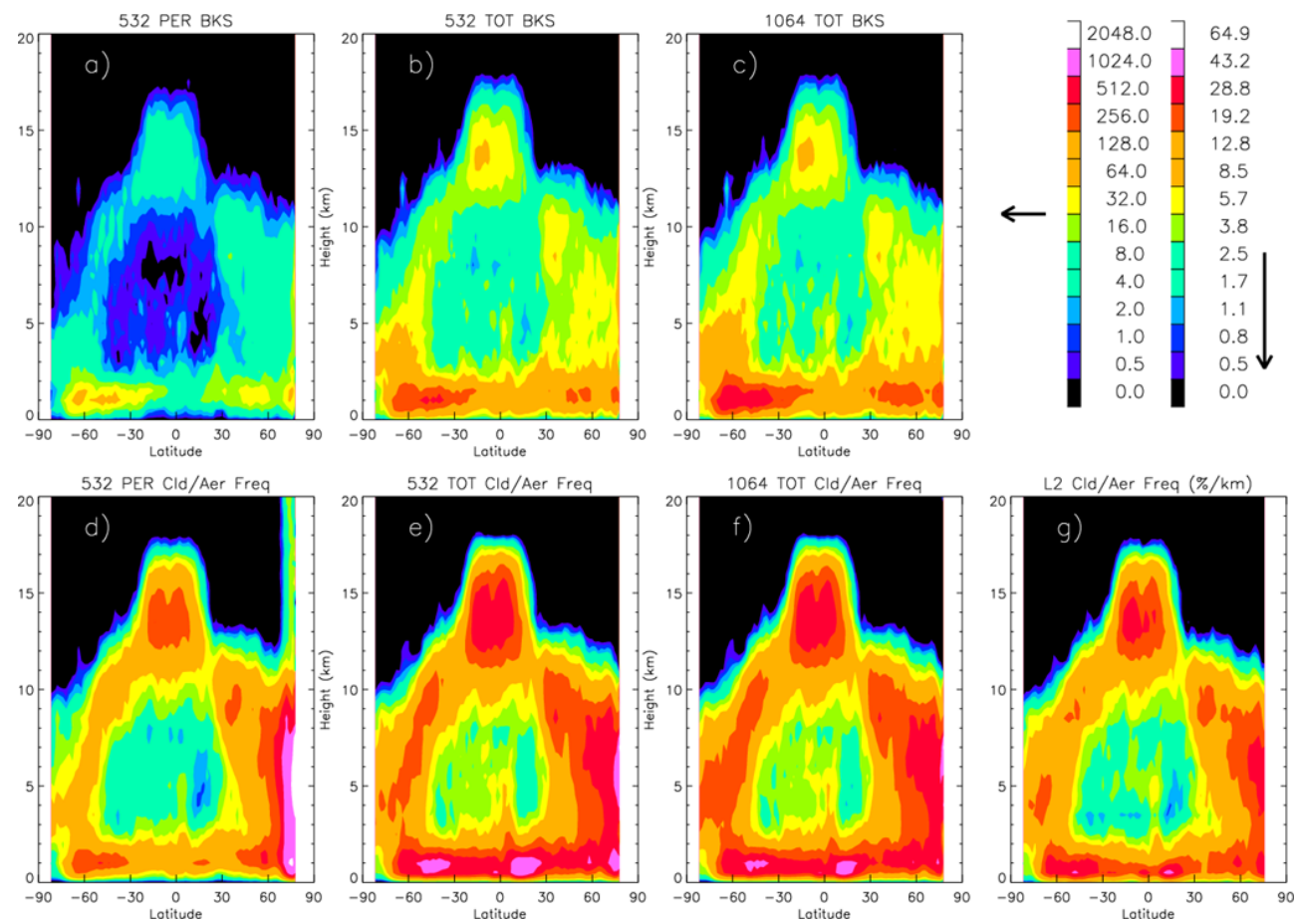

Fig. 10. Daytime zonal mean backscatter and cloud/aerosol occurrence frequency for January 2008. (a)-(c): the zonal mean 532-nm PER, 532-nm TOT, and 1064-nm TOT attenuated backscatter in $\mathrm{km}^{-1} \mathrm{sr}^{-1}$; (d)-(f): the corresponding occurrence frequencies by altitude (in\% per $\mathrm{km}$ ) for cloud/aerosol features detected from these channels; and (g): the total occurrence frequency of clouds and aerosols from the L2_CLay and L2_ALay data. The colors for backscatter and frequency have units of $\mathrm{km}^{-1} \mathrm{sr}^{-1}$ and\% per km, respectively.

different spatial averaging is used. For example, studying the CALIOP data jointly with other A-Train sensors (e.g., MLS) may require further aggregating the CALIOP data to have a matched measurement volume. In that case, the feature detection thresholds need to be re-evaluated.

Shown in Figs. 10-11 are zonal mean statistics of the January $2008 \mathrm{cloud} /$ aerosol features detected with the Table $1 \sigma$ method. The mean feature backscatter is computed from the background-corrected values, i.e., $\Delta \beta(z)$, and averaged into a $2^{\circ}$ latitude and $0.5 \mathrm{~km}$ altitude bin, along with the mean feature occurrence frequency. The zonal mean backscatter and occurrence frequency exhibit a similar, consistent distribution in general. Compared to the results from the L2 $05 \mathrm{~km} \_C L a y$ and $05 \mathrm{~km} \_A L a y$ products (Figs. $10 \mathrm{~g}$ and $11 \mathrm{~g}$ ), the occurrence frequencies obtained in this study (Figs. 10e and $11 \mathrm{e})$ are slightly higher.

However, the occurrence frequencies from the two methods differ significantly in the UT/LS where feature occurrence frequency and signal-to-noise ratio are low. These features are important for studying cloud, aerosol, and water vapor changes related to troposphere-stratosphere exchanges. In particular, their spatial/temporal variations and day-night differences provide valuable insights to the problem, but impacts of the measurement noise must be fully understood and characterized at first. Figures 12-14 summarize the monthly feature and noise statistics in the tropical UT/LS.
Figure 12 shows the seasonal variation of monthly mean feature backscatter and occurrence frequency at $15 \mathrm{~km}$ from the research algorithm presented in this study and from the L2 algorithm. The daytime 532-nm and 1064-nm TOT have similar monthly mean backscatters. A 1064/532 color ratio is calculated from the monthly averages, varying between 1.0 and 1.2 with a slight decreasing trend in both day and night data. In addition, the daytime color ratio exhibits a large seasonal cycle, which is absent in the nighttime data. Similarly, a 532-nm depolarization ratio $(\delta)$ is derived from the monthly mean 532-nm PER and TOT data, showing $\sim 0.3$ for day and $\sim 0.45$ for night with a very small seasonal variation. Sassen and Zhu (2009) reported a slightly larger $(\sim 0.41)$ daytime $\delta$ at $15 \mathrm{~km}$ in the tropics, and a smaller $(\sim 0.28)$ nighttime $\delta$, using the attenuated backscatters not corrected by the molecular background. They also reported an enhanced nighttime $\delta$ values in the SAA region. Since the nighttime feature detection with the 532-nm PER channel, the nighttime $\delta$ is sensitive to the measurement noise and the threshold used. Similarly, the day-night difference in feature occurrence frequency also depends strongly on the threshold used. As seen in Fig. 12, despite the similar mean backscatter values, the occurrence frequencies differ by approximately a factor of 2 .

An increasing trend is evident in the 1064-nm noise during 2006-2008 (Fig. 13), which may explain the decreasing color ratio seen at $15 \mathrm{~km}$ and the increasing occurrence frequency 

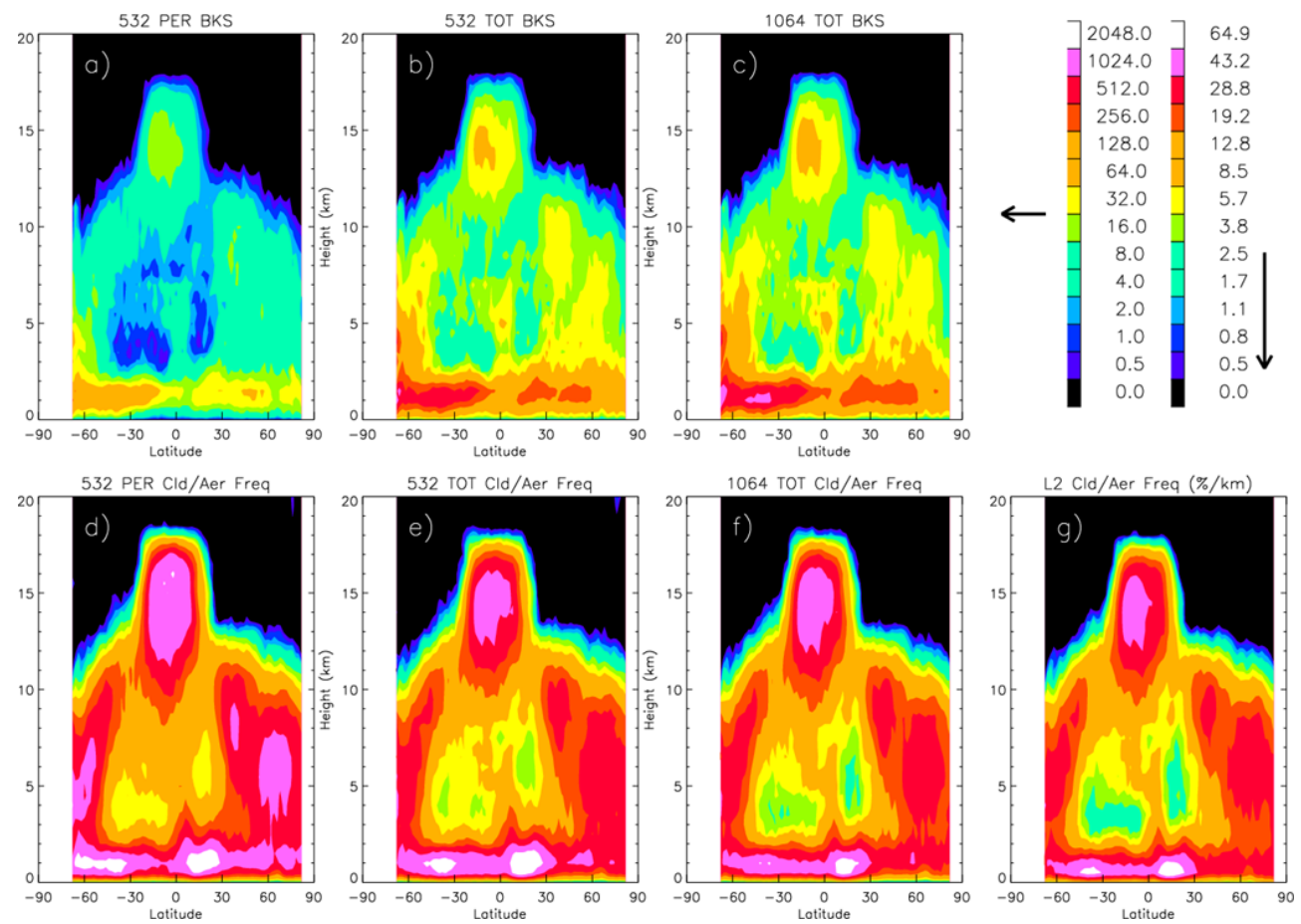

Fig. 11. As in Fig. 10 but for the nighttime data. In the nighttime 532-nm PER statistics, despite the aggressive screening threshold (80 $\sigma)$, a fraction $(\sim 0.5 \%)$ of stratospheric features (not PSCs) are still present at middle latitudes, which warrants further investigation.

differences between the 532- and 1064-nm channels as seen in Fig. 12. Although the daytime noises $\left(\sigma_{1064 \_ \text {TOT }}>\right.$ $\left.\sigma_{532 \_ \text {TOT }}>\sigma_{532 \_ \text {PER }}\right)$ have a similar seasonal variation, the nighttime $\sigma$ values differ by more than an order of magnitude. The increasing trend in nighttime $\sigma_{1064 \text { _TOT is consis- }}$ tent with the expectation of the dark count increase in the channel (Hunt et al., 2009). Important for a trend analysis,

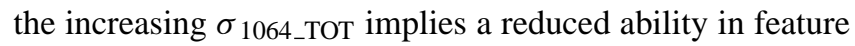
detection with this channel. The slightly increasing difference between the 532- and 1064-nm occurrence frequencies at $15 \mathrm{~km}$, as well as the decreasing color ratio in Fig. 12, is likely resulted from this degraded sensitivity in the 1064-nm channel.

At altitudes near and above the tropopause, where feature occurrence frequency drops sharply with height, various detection methods begin to show large differences. As seen in Fig. 14, this study produces a larger daytime frequency at 18 $19 \mathrm{~km}$ than the L2. At $19 \mathrm{~km}$ the research algorithm produces a residual frequency of $0.04 \% / \mathrm{km}$ for day and $0.06 \% / \mathrm{km}$ for night in the $532-\mathrm{nm}$ TOT data, compared to $0.0005 \% / \mathrm{km}$ and $0.001 \% / \mathrm{km}$ from the $\mathrm{L} 2$ data. To a large extent, the values at $19 \mathrm{~km}$ reflect the false-positive detection rate. As an independent estimate for the false detection rate, the negative PDF domain is used to compute the probability in the distribution tail beyond the Table 1 threshold values. This estimation yields a rate of $\sim 0.1 \% / \mathrm{km}$ for day and $0.05 \% / \mathrm{km}$ for night, which is comparable to the values obtained at $19 \mathrm{~km}$, but much higher than what result from a pure Gaussian noise.
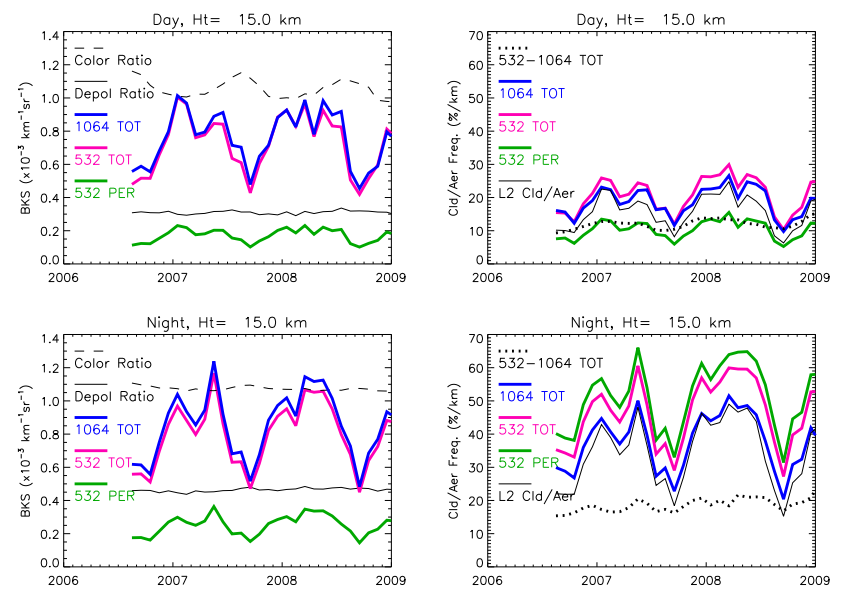

Fig. 12. Time series of day (top) and night (bottom) monthly mean backscatter (left) and feature occurrence frequency (right) at $15 \mathrm{~km}$ altitude in the $10^{\circ} \mathrm{S}-10^{\circ} \mathrm{N}$ latitude bin. For the 532-nm and 1064-nm TOT backscatters, the molecular background have been removed. The 532-nm depolarization ratio $\left(\delta=\beta_{\perp} / \beta_{l l}\right)$ and the $1064 / 532$ color ratio are calculated from the monthly means. Time series of the occurrence frequencies from 532-nm and 1064-nm channels, as well as the frequency difference, are shown in the right panels where the L2 $05 \mathrm{~km}$ (CLay+ALay) results are included for comparison. 


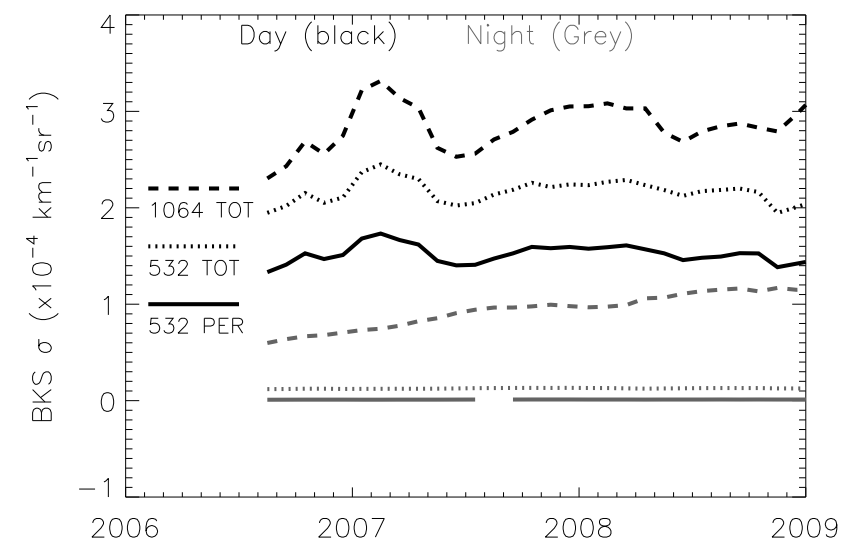

Fig. 13. Time series of monthly mean $\sigma$ of the 532-nm PER, 532$\mathrm{nm}$ TOT and 1064-nm TOT backscatter for the $10^{\circ} \mathrm{S}-10^{\circ} \mathrm{N}$ latitude bin. An increasing trend is evident in the nighttime 1064-nm $\sigma$, consistent with the dark count increase reported by Hunt et al. [2009].
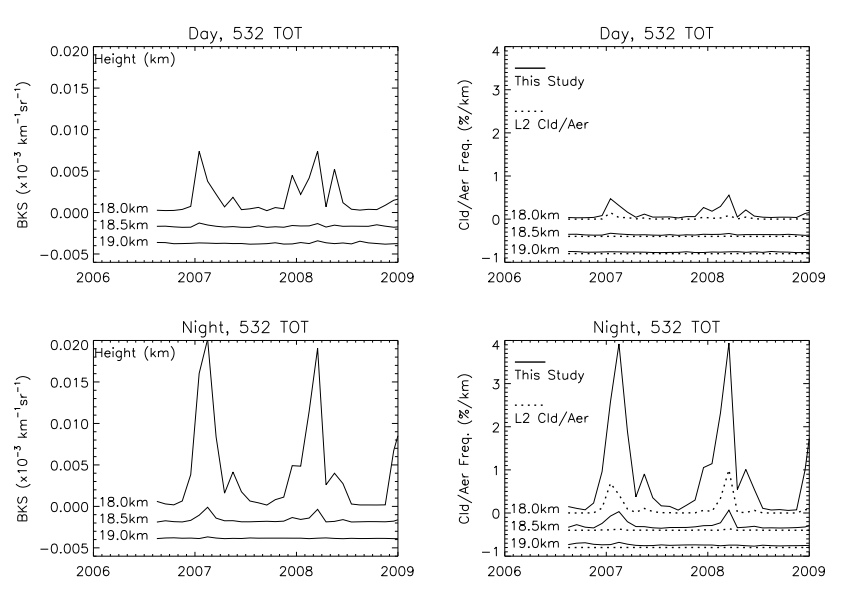

Fig. 14. Seasonal variations of the features detected from the 532$\mathrm{nm}$ TOT backscatter near the tropical $\left(10^{\circ} \mathrm{S}-10^{\circ} \mathrm{N}\right)$ tropopause where the occurrence frequency drops sharply with height. Monthly mean backscatters (left panels) are plotted for altitudes 18, 18.5 and $19 \mathrm{~km}$ with an increment offset of $0.002 \mathrm{~km}^{-1} \mathrm{sr}^{-1}$, whereas monthly mean occurrence frequencies (right panels) are offset by an increment of $0.4 \% / \mathrm{km}$ for the different altitudes. The daytime (nighttime) mean occurrence frequencies at $19 \mathrm{~km}$ are 0.04 $(0.06) \% / \mathrm{km}$ from this study, compared to $0.005(0.001) \% / \mathrm{km}$ from the L2 data.

Since the nighttime measurement has lower noise, its seasonality at $18 \mathrm{~km}$ is believed to be more reliable. In this study we find that the seasonal variations of the night backscatter and the occurrence frequency are very similar at these altitudes. Analyzing the CALIOP data from June 2006 to February 2007, Fu et al. (2007) found no clouds above $19 \mathrm{~km}$ and observed a $\sim 0.05 \%$ occurrence frequency at $18.5 \mathrm{~km}$ and $0.5 \%$ at $18 \mathrm{~km}$. This study shows that the $0.1 \%$ per km level is close to the noise floor or the stratospheric background, and the TTL (tropical tropopause layer) top has a strong seasonal variation, as expected for deep convective climatology. In the case where the desired signals are close to the noise floor, the convolution of signal and noise statistics would make comparisons of different data sets more challenging.

The day-night differences at $18 \mathrm{~km}$ in Fig. 14 are mostly caused by the different detection thresholds used for the daytime and nighttime data. For the weak signals like these, Wu et al. [2009] suggested to compare statistics of the two datasets with the normalized PDF approach. This method requires that two data sets have the same measurement volume and the same ensemble. One of the advantages with this method is avoidance of artificially-imposed feature detection thresholds. As long as these data sets represent the same statistical ensemble with a sufficient number of samples, the PDF comparisons will yield useful characterization on measurement noise, bias, sensitivity limitation, and cloud/aerosol statistics of the ensemble.

In Fig. 15 we compare the normalized PDFs of CALIOP day and night backscatter measurements. Because the CALIOP noise differs substantially between day and night, we compare the day-night difference of probability density at each backscatter value above the daytime (or larger) noise level. As in Fig. 7, the noise PDF in Fig. 15 is the rising probability density at small values with a Gaussian-like distribution. At the backscatter values greater than the daytime noise (e.g., $10^{-2}-10^{-1.5} \mathrm{~km}^{-1} \mathrm{sr}^{-1}$ ), as shown in Fig. 15, the day PDF stands clearly above the night one at altitudes $>10 \mathrm{~km}$, suggesting that these daytime features have a higher occurrence frequency. At very large backscatter values, the PDF is too low and the difference becomes noisier, whereas at very small values the daytime noise prohibits the comparison.

Thus, the day-night difference of feature occurrence frequency inferred from Fig. 15 is opposite to the thresholdbased results as shown in Fig. 14. In an early study with the ICESat data [Dessler et al., 2006], the nighttime cirrus fraction was found to be higher than the daytime, which was resulted mostly from the different detection thresholds used. Recently, by the same token, Liu and Zipser (2009) analyzed the CALIOP L2 cloud data and reported the similar higher nighttime cloud fraction. As aforementioned, if the $>5 \sigma$ threshold were used for CALIOP day and night measurements, the nighttime feature fraction would be higher than the daytime, which is not consistent with the PDF analysis in Fig. 15. The day-night difference is likely dependent on water vapor and temperature, and therefore on cloud ice water content (IWC). As revealed in Fig. 15, if one uses the backscatter as a proxy of IWC, the day-night difference varies with the backscatter value, which can be related to the type of ice clouds and/or to the process controlling cloud formation. In addition, the PDF analysis may provide a promising alternative to characterize other cloud/aerosol statistics, such as depolarization and color ratios, where the measurement noise is highly non-stationary and different between two data sets. 

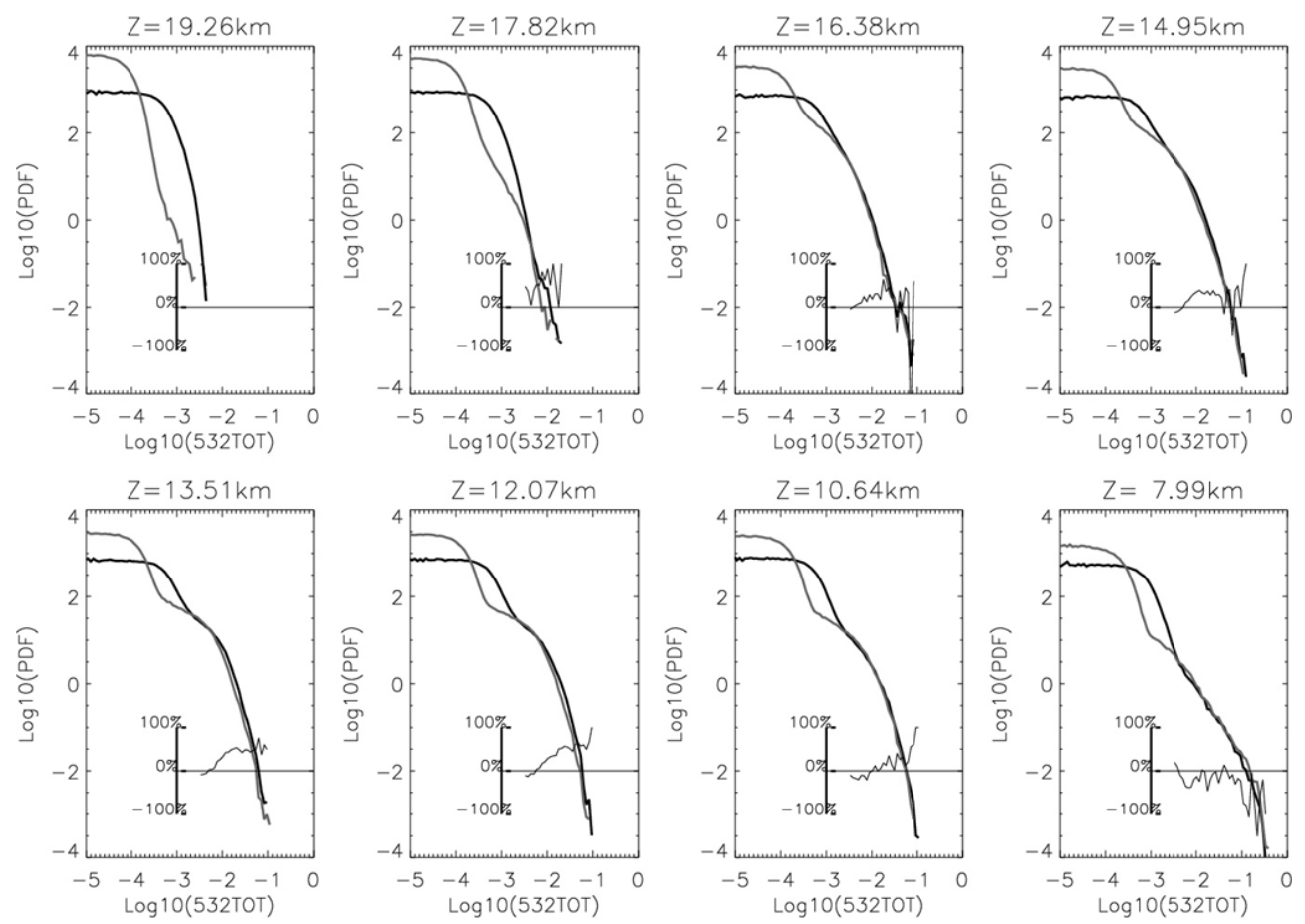

Fig. 15. Day-night differences at the tropics $\left(10^{\circ} \mathrm{S}-10^{\circ} \mathrm{N}\right)$ as revealed in the normalized PDFs of the attenuated 532-nm TOT backscatter for January 2008. Day and night PDFs are denoted by the dark and grey curve, respectively, whereas the thin line beneath PDF curves is the percentage PDF difference. The rising PDF at small values is a manifestation of the noise distribution. The day-night PDF differences are not shown when the backscatter is $<5 \sigma$ of the daytime noise. The day PDFs are generally higher than those at night except at $7.99 \mathrm{~km}$.

\section{Conclusions and future work}

Noise characteristics of the calibrated CALIOP 532-nm and 1064-nm attenuated backscatters were investigated with two approaches. One is to fit the CALIOP clear-sky backscatter data by scaling them to the molecular scatter model, and study variations of the scaling factor $(\alpha)$ derived from the v2.01 and v2.02 data. The other is to estimate the measurement noise using the calibrated backscatter data at altitudes of $19-40 \mathrm{~km}$ and assuming $\alpha=1$. Maps and time series of the measurement noise properties are analyzed in terms of the mean $(\mu)$ and standard deviation $(\sigma)$. The derived $\sigma$ provides a reliable representation of the lidar measurement noise at lower altitudes, and we it to develop a $\sigma$-based research algorithm for cloud/aerosol feature detection with the thresholds given in Table 1. This method is applied to the aggregated CALIOP L1 data at the fixed 5-km horizontal resolution. Variations of the measurement noises and their impacts on cloud/aerosol detection are discussed. In addition, the normalized PDF approach is employed to evaluate daynight differences in the lidar data of which the noise properties are quite different. The major findings and conclusions from this study are summarized as follows.

1. The lidar backscatter noises exhibit large profile-toprofile variability in $\sigma$, more pronounced in the daytime data. Such transiency was found in all the CALIOP channels. Maps of the January 2008 noise properties show that the daytime noises are significantly higher over landmasses and bright surfaces (e.g., snow, ice and desert), reflecting large variability in additional sunlight scattering during day. This large noise variability appears to be more pronounced in the 1064-nm TOT measurements than in the 532-nm data. On the other hand, the nighttime noises, although generally lower than daytime, are enhanced in the radiation-hard regions (e.g., SAA and auroral ovals), but only in the 532-nm not 1064-nm data.

2. The scaling $\alpha$ approach demonstrated some promising capabilities for evaluating and diagnosing error in the calibrated 532-nm and 1064-nm data. The nighttime 532-nm $\alpha$ values are mostly close (within 5\%) to unity, whereas the daytime 532-nm values are within $10 \%$. The daytime 532-nm $\alpha$ values show an abrupt drop in October 2008, which is likely associated with some changes in the 532-nm backscatter calibration. The 1064-nm $\alpha$ values are mostly between 2 and 3 with the daytime numbers being systematically higher.

3. Most of the CALIOP backscatter noises have a Gaussian-like distribution, except for the nighttime 532nm PER measurements. The latter have the lowest $\sigma$ but with a double Gaussian-like distribution. The 
distribution of the measurement noise is a combination of detector/calibration error and enhanced photon noise from the sunlight.

4. At $\sim 16 \mathrm{~km}$ the nighttime PDFs from the $532-\mathrm{nm}$ and 1064-nm TOT backscatters show a drastic change in slope near the value of $\sim 10^{-2.5}$ or $\sim 0.003 \mathrm{~km}^{-1} \mathrm{sr}^{-1}$, which appears not due to the attenuation by feature layers. This transition in the PDF slope is difficult to observe with the daytime data due to the large solar background noise. This PDF transition divides the feature statistics into the domains, which might be useful for studying cirrus generation and life cycle in the TTL (tropical tropopause layer) region. Further investigations with the CALIOP, CloudSat, and MLS data could provide more insights to this transition.

5. As a research algorithm, a $\sigma$-based detection method using the thresholds in Table 1 was developed to detect cloud/aerosol features from the aggregated CALIOP data. The method was able to produce morphology similar to that from the CALIPSO L2 products but showed slightly higher percentages than the Level 2 results.

6. The observed feature seasonal variations in the TTL region are generally consistent among all the CALIOP channels. However, there is an increasing difference between the 532-nm and 1064-nm occurrence frequencies, which may be associated with the increasing noise in the 1064-nm channel.

7. An analysis with the normalized PDFs on the daynight difference in January 2008 suggest a higher occurrence frequency at 1:30 p.m. than at 1:30 a.m. in the TTL region. This is opposite to the result inferred from the $\sigma$-based detection method if different thresholds are used, but would be consistent with the result if a fixed and larger-than-daytime-noise threshold were used (e.g., $0.003 \mathrm{~km}^{-1} \mathrm{sr}^{-1}$ ).

By reducing the data volume of the original CALIOP Level 1 data, we are able to process a large quantity of the lidar data and study long-term variability of cloud/aerosol features as well as the measurement noise. With a better understanding of the measurement noise in the aggregated data, we are able to further investigate the CALIOP data in conjunction with other A-train observations (e.g., CloudSat and Aura MLS) to study cloud/aerosol variations in the UT/LS region. The research algorithm developed here can be readily applied to future multi-sensor studies with different spatial averaging and detection thresholds if needed. As suggested in Jiang et al. [2008], cloud ice particle sizes may vary with polluted and clean environments as pollution aerosols can make their way into the UT/LS (Li et al., 2005; Fu et al., 2006; Park et al., 2009; Wu et al., 2010). Because cloud/aerosol occurrence reduces sharply near the tropopause, accurate and careful statistical analyses are required to extract these weak signals.
This study provides an initial evaluation on the CALIOP measurement noise and sensitivity in the UT/LS region, of which the results will used to guide future studies involving different spatial averaging and detection thresholds.

Acknowledgements. This work was performed at the Jet Propulsion Laboratory, California Institute of Technology, under contract with the National Aeronautics and Space Administration (NASA). We would like to thank Z. Liu, Y. Hu, W. Hunt, C. Trepte, M. Vaughan, and D. Winker for helpful discussions on CALIPSO instrument and data analysis. The data processing and distribution by the NASA Langley Research Center Atmospheric Sciences Data Center are gratefully acknowledged.

Edited by: T. J. Dunkerton

\section{References}

Anselmo, T.: Cloud - Aerosol LIDAR Infrared Pathfinder Satellite Observations: Data Management System, Data Products Catalog. Document No: PC-SCI-503, NASA, Langley Research Center, Hampton, VA, USA, 2006.

Comstock, J. M., d'Entremont, R., DeSlover D., Mace, G. G., Matrosov, S. Y., McFarlane, S. A., Minnis, P., Mitchell, D., Sassen, K., Shupe, M. D., Turner, D. D., and Wang, Z.: An intercomparison of microphysical retrieval algorithms for upper-tropospheric ice clouds, Bull. Am. Meteorol. Soc., 88, 191-204, 2007.

Dessler, A. E., Palm, S. P., Hart, W. D., and Spinhirne, J. D.: Tropopause-level thin cirrus coverage revealed by ICESat/Geoscience Laser Altimeter System, J. Geophys. Res., 111, D08203, doi:10.1029/2005JD006586, 2006.

Dessler, A. E., Zhang, Z., and Yang, P.: Water-vapor climate feedback inferred from climate fluctuations, 2003-2008, Geophys. Res. Lett., 35, L20704, doi:10.1029/2008GL035333, 2008.

Jensen, E. J. and Ackerman, A. S.: Homogeneous aerosol freezing in the tops of high-altitude tropical cumulonimbus clouds. Geophys. Res. Lett., 33, L08802, doi:10.1029/2005GL024928, 2006.

Jensen, E. J., Toon, O. B., Selkirk, H. B., Spinhirne, J. D., and Schoeberl, M. R.: On the formation and persistence of subvisible cirrus clouds near the tropical tropopause, J. Geophys. Res., 101, 21361-21375, 1996.

Jiang, J. H., Su, H., Schoeberl, M., Massie, S. T., Colarco, P., Platnick, S., and Livesey, N.: Clean and polluted clouds: relationships among pollution, ice cloud and precipitation in South America, Geophys. Res. Lett. 35, L14804, doi:10.1029/2008GL034631, 2008.

Fromm, M. D.: Plumes cover the northern hemisphere: lidar views of summer 2008 volcanic and pyroconvective injections, AGU Fall Meeting, Section A52A, 2008.

$\mathrm{Fu}, \mathrm{Q}$., Hu, Y., and Yang, Q.: Identifying the top of the tropical tropopause layer from vertical mass flux analysis and CALIPSO lidar cloud observations, Geophys. Res. Lett., 34, L14813, doi:10.1029/2007GL030099, 2007.

Fu, R., Hu, Y., Wright, J. S., Jiang, J. H., Dickinson, R. E., Chen, M., Filipiak, M., Read, W. G., Waters, J. W., and Wu, D. L.: Short circuit of water vapor and polluted air to the global stratosphere by convective transport over the Tibetan Plateau, Proc. Natl. Acad. Sci., 103, 5664-5669, 2006. 
Fueglistaler, S., Dessler, A. E., Dunkerton, T. J., Folkins, I., Fu, Q., and Mote, P. W.: The Tropical Tropopause Layer, Rev. Geophys. 47, RG1004, doi:10.1029/2008RG000267, 2009.

Hunt, W. H., Winker D. M., Vaughan, M. A., Powell, K. A., Lucker, P. L., and Weimer, C.: CALIPSO lidar description and performance assessment, J. Atmos. Oceanic Technol., 26(7) 12141228, 2009.

Li, Q. B., Jiang, J. H., Wu, D. L., Read, W. G., Livesey, N. J., Waters, J. W., Zhang, Y. S., Wang, B., Filipiak, M. J., Davis, C. P., Turquety, S., Wu, S. L., Park, R. J., Yantosca, R. M., and Jacob, D. J.: Convective outflow of South Asian pollution: A global CTM simulation compared with EOS MLS observations, Geophys. Res. Lett. 32, L14826, doi:10.1029/2005GL022762, 2005.

Liu, C. and Zipser, E. J.: Implications of the day versus night differences of water vapor, carbon monoxide, and thin cloud observations near the tropical tropopause, J. Geophys. Res., 114, D09303, doi:10.1029/2008JD011524, 2009.

Liu, Z. Y., Vaughan, M. A., Winker, D. M., Hostetler, C. A., Poole, L. R., Hlavka, D., Hart, W., and McGill, M.: Use of probability distribution functions for discriminating between cloud and aerosol in lidar backscatter data, J. Geophys. Res., 109, D15202, doi:10.1029/2004JD004732, 2004.

Liu, Z. Y., Hunt, W., Vaughan, M., Hostetler, C., McGill, M., Powell, K., Winker, D., and Hu, Y. X.: Estimating random errors due to shot noise in backscatter lidar observations. APPLIED OPTICS, 45(18), 4437-4447, 2006.

Liu, Z. Y., Vaughan, M., and Winker, D.: The CALIPSO lidar cloud and aerosol discrimination: Version 2 algorithm and initial assessment of performance, J. Atmos. Oceanic Technol., 26 (7), 1198-1213, 2009.

Lohmann U. and Roeckner, E.: Influence of cirrus cloud radiative forcing on climate and climate sensitivity in a general circulation model. J. Geophys. Res., 100, 16305-16323, 1995.

Mishchenko, M. I., Geogdzhayev, I. V., Rossow, W. B., Cairns, B., Carlson, B. E., Lacis, A. A., Liu, L., and Travis, L. D.: LongTerm Satellite Record Reveals Likely Recent Aerosol Trend, Science, 315, 1543, doi:10.1126/science.1136709, 2007.

Park, M., Randel, W. J., Emmons, L. K., and Livesey, N. J.: Transport pathways of carbon monoxide in the Asian summer monsoon diagnosed from Model of Ozone and Related Tracers (MOZART), J. Geophys. Res. 114, D08303, doi:10.1029/2008JD010621, 2009.

Powell, K. A., Hostetler, C. A., Liu, Z. Y., Vaughan, M. A., Kuehn, R. E., Hunt, W. H., Lee, K. P., Trepte, C. R., Rogers, R. R., Young, S. A., and Winker, D. M.: CALIPSO lidar calibration algorithms: Part I - Nighttime $532 \mathrm{~nm}$ parallel channel and $532 \mathrm{~nm}$ perpendicular channel, J. Atmos. Ocean. Technol., 26(10), 20152033, 2009.

Sassen, K. and Zhu, J.: A global survey of CALIPSO linear depolarization ratios in ice clouds: Initial findings, J. Geophys. Res., 114, D00H07, doi:10.1029/2009JD012279, 2009.

Sherwood, S. C.: A microphysical connection among biomass burning, cumulus clouds, and stratospheric moisture. Science, 295, 1272-1275, 2002.
Stephens, G. L., Vane, D. G., Tanelli, S., Mace, G. G., Sassen, K., Wang, Z. E., Illingworth, A. J., O'Connor, E. J., Rossow, W. B., Durden, S. L., Miller, S. D., Austin, R. T., Benedetti, A., and Mitrescu, C.: The CloudSat mission and the EOS constellation: A new dimension of space-based observations of clouds and precipitation. B. Am. Meteorol. Soc., 83, 1771-1790, 2002.

Tanelli, S., Durden, S. L., Im, E., Pak, K. S., Reinke, D. G., Partain, P., Haynes, J. M., and Marchand, R. T.: CloudSat's Cloud Profiling Radar after two years in orbit: performance, external calibration, and processing, IEEE Trans. Geos. Remote Sens., 48, 3560-3573, 2008.

Thomason, L. W. and Pitts, M. C.: CALIPSO observations of volcanic aerosol in the stratosphere, Proc. of SPIE, 7153, 71530O-7, 2008.

Vaughan, M., Powell, K. A., Kuehn, R. E., Yong, S. A., Winker, D. M., Hostetler, C. A., Hunt, W. H., Liu, Z. Y., McGill, M. J., and Getzewich, B. J.: Fully Automated Detection of Cloud and Aerosol Layers in the CALIPSO Lidar Measurements. J. Atmos. Ocean. Technol., 26, 2034-2050, 2009.

Winker, D. M., Pelon, J., and McCormick, M. P.: The CALIPSO mission: Spaceborne lidar for observation of aerosols and clouds, Proc. SPIE Int. Soc. Opt. Eng., 4893, 1-11, 2003.

Winker, D. M., Hunt, W. H., and McGill, M. J.: Initial performance assessment of CALIOP, Geophys. Res. Lett., 34, L19803, doi:10.1029/2007GL030135, 2007.

Winker, D. M., Vaughan, M. A., Omar, A., Hu, Y. X., Powell, K. A., Liu, Z. Y., Hunt, W. H., and Young, S. A.: Overview of the CALIPSO Mission and CALIOP Data Processing Algorithms, J. Atmos. Ocean. Technol., 26, 2310-2323, 2009.

Vernier, J. P., Pommereau, J. P., Garnier, A., Pelon, J., Larsen, N., Nielsen, J., Christensen, T., Cairo, F., Thomason, L. W., Leblanc, T., and McDermid, I. S.: Tropical stratospheric aerosol layer from CALIPSO lidar observations, J. Geophys. Res., 114, D00H10, doi:10.1029/2009JD011946, 2009.

Young, S. A. and Vaughan, M. A.: The retrieval of profiles of particulate extinction from Cloud Aerosol Lidar Infrared Pathfinder Satellite Observations (CALIPSO) data: Algorithm description. J. Atmos. Oceanic Technol., 26, 1105- 1119, 2009.

Wu, D. L., Jiang, J. H., Read, W. G., Austin, R. T., Davis, C. P., Lambert, A., Stephens, G. L., Vane, D. G., and Waters, J. W.: Validation of the Aura MLS Cloud Ice Water Content (IWC) Measurements, J. Geophys. Res. 113, doi:10.1029/2007JD008931, 2008.

Wu, D. L., Austin, R. T., Deng, M., Durden, S. L., Heymsfield, A. J., Jiang, J. H., Lambert, A., Li, J. L., Livesey, N. J., McFarquhar, G. M., Pittman, J. V., Stephens, G. L., Tanelli, S., Vane, D. G., and Waliser, D.E.: Comparisons of Global Cloud Ice from MLS, CloudSat, and Correlative Data Set, J. Geophys. Res., CloudSat special section, 114, D00A24, doi:10.1029/2008JD009946, 2009. 